\title{
Editorial
}

\section{Erectile dysfunction in the Africa/Middle East Region: epidemiology and experience with sildenafil citrate (Viagra ${ }^{\circledR}$ )}

\author{
International Journal of Impotence Research (2003) 15, Suppl 1, S1-S2. doi:10.1038/sj.ijir.3900967
}

\section{Introduction}

The worldwide prevalence of erectile dysfunction (ED) is very high and is expected to increase substantially over the next 25 years. Ayta et $a l^{1}$ have applied the results of the Massachusetts Male Aging Study (MMAS) ${ }^{2}$ to world population data and estimated that the worldwide prevalence of ED in 1995 exceeded 152 million men, and that this number should reach 322 million by $2025 .{ }^{1}$ Perceptions about male sexual function and the effects of ED on quality of life may differ significantly from one culture to another. ${ }^{3}$ Most of our current information regarding the prevalence/consequences of ED and efficacy of different therapies has been derived from epidemiologic studies and clinical trials carried out in Western Europe, North America, and Japan. It is clear that ED is a worldwide problem and that its prevalence and impact, and the efficacy of different therapies, should be studied across a wide range of patients from all countries. It is particularly important that ED and its treatment be studied in cultures different from those of the industrialized nations in which nearly all largescale and well-controlled studies have been carried out to date. The purpose of this supplement is to extend the study of ED and therapies for this condition to countries where they have received relatively little attention.

The first two studies in the supplement are concerned with the epidemiology of ED in nonWestern countries. In a population-based study, Berrada et $\mathrm{I}^{4}$ evaluated the incidence and correlates of ED in 655 randomly selected men over $25 \mathrm{y}$ of age residing in Casablanca, Morocco. Study results indicated that the incidence of, risk factors for, and comorbidities of ED in this cohort were very similar to those reported for Western societies. ${ }^{2,5,6}$ The overall prevalence of ED among those men evaluated was $54 \%$ and its incidence increased markedly with age. Risk factors for ED in this group included diabetes, hypertension, heart disease, and smoking behavior.

Shaeer and colleagues ${ }^{7}$ also evaluated the incidence of ED among men attending primary health care clinics in countries with cultures very different from those in the industrialized West: Pakistan, Egypt, and Nigeria. The results of this epidemiologic analysis, like that of Berrada et al, ${ }^{4}$ indicated that the prevalence of ED and other diseases associated with this condition in sub-Saharan Africa, the Middle East, and south Asia is similar to that in the United States and Western Europe. Surveys of men between 35 and 70 y of age seeking primary medical care indicated that the age-adjusted prevalences of ED were $57.4 \%$ in Nigeria, $63.6 \%$ in Egypt, and $80.8 \%$ in Pakistan. As in other studies, ${ }^{2,5}$ older age, diabetes, prostate conditions, and depression were all associated with increased risk for ED.

The other studies in this supplement all evaluated the efficacy and safety of sildenafil citrate (Viagra ${ }^{\circledR}$ ) for the treatment of ED in non-Western men. It is of interest to note that the results of all of these trials demonstrated efficacy for sildenafil similar to that which has been reported in large studies carried out in the United States and Western Europe. ${ }^{8,9}$

Osegbe et $a l^{10}$ evaluated the effectiveness of oral therapy with sildenafil in 58 Nigerian men with ED, some of whom also had diabetes and/or hypertension, and reported significant improvements in erectile function and overall satisfaction similar to those observed in Western trials. Sildenafil was also well tolerated by the patients in this study. Benchekroun et $a l^{11}$ reported similar beneficial effects of sildenafil in a study that included 71 Moroccan men with ED. In this 12-week flexibledose study, sildenafil treatment significantly improved both erectile function and quality of life. Sildenafil was also well tolerated, with few treatment-emergent adverse events. Moreover, in a final 12-week randomized, double-blind, placebo-controlled, parallel-group, flexible-dose study that included 254 men with ED from either Egypt or South Africa, Levinson et $a l^{12}$ showed that sildenafil significantly improved erections versus placebo and that it was also well tolerated.

The information contained in this supplement supports the view that ED is a worldwide problem with a prevalence in developing countries similar to, if not higher than, that reported for men in industrialized societies. These findings are consistent 
with other epidemiologic studies carried out in Asia and Latin America. ${ }^{13,14}$ Clinical trial results showed further that oral therapy with sildenafil, now established as the treatment of choice for ED, is also highly effective in individuals from developing countries with cultural, racial, and religious characteristics differing markedly from those of the United States and European countries in which the pivotal trials that initially established the effectiveness and safety of sildenafil were carried out.

IM Khalaf and IP Levinson

Guest Editors

\section{References}

1 Ayta IA, McKinlay JB, Krane RJ. The likely worldwide increase in erectile dysfunction between 1995 and 2025 and some possible policy consequences. BJU Int 1999; 84: 50-56.

2 Johannes CB et al. Incidence of erectile dysfunction in men 40 to 69 years old: longitudinal results from the Massachusetts Male Aging Study. J Urol 2000; 163: 460-463.

3 Masumori $\mathrm{N}$ et al. Decline of sexual function with age in Japanese men compared with American men - results of two community-based studies. Urology 1999; 54: $335-344$

4 Berrada S, Kadri N, Mechakra-Tahiri S, Nejjari C. Prevalence of erectile dysfunction and its correlates: a population-based study in Morocco. Int J Impot Res 2003; 15(Suppl 1): S3-S7.

5 Braun $\mathrm{M}$ et al. Epidemiology of erectile dysfunction: results of the ‘Cologne Male Survey'. Int J Impot Res 2000; 12: 305-311.
6 Martin-Morales A et al. Prevalence and independent risk factors for erectile dysfunction in Spain: results of the Epidemiologia de la Disfuncion Erectil Masculina Study. J Urol 2001; 166: 569-574.

7 Shaeer KZM et al. Prevalence of erectile dysfunction and its correlates among men attending primary care clinics in three countries: Pakistan, Egypt, and Nigeria. Int J Impot Res 2003; 15(Suppl 1): S8-S14

8 Padma-Nathan H, Steers WD, Wicker PA. Efficacy and safety of oral sildenafil in the treatment of erectile dysfunction: a double-blind, placebo-controlled study of 329 patients. Sildenafil Study Group. Int J Clin Pract 1998; 52: $375-379$

9 Montorsi $\mathrm{F}$ et al. Efficacy and safety of fixed-dose oral sildenafil in the treatment of erectile dysfunction of various etiologies. Urology 1999; 53: 1011-1018.

10 Osegbe DN et al. Sildenafil citrate (Viagra ${ }^{\circledR}$ ) for the treatment of erectile dysfunction in Nigerian men. Int J Impot Res 2003; 15(Suppl 1): S15-S18.

11 Benchekroun A et al. A baseline-controlled, open-label, flexible dose-escalation study to assess the safety and efficacy of sildenafil citrate (Viagra ${ }^{\mathbb{R}}$ ) in patients with erectile dysfunction. Int J Impot Res 2003; 15(Suppl 1): S19-S24.

12 Levinson IP, Khalaf IM, Shaeer KZM, Smart DO on behalf of the African Sildenafil Study Group. Efficacy and safety of sildenafil citrate $\left(\right.$ Viagra ${ }^{\mathbb{R}}$ ) for the treatment of erectile dysfunction in men in Egypt and South Africa. Int $J$ Impot Res 2003; 15(Suppl 1): S25-S29.

13 Thai Erectile Dysfunction Epidemiologic Study Group (TEDES). An epidemiological study of erectile dysfunction in Thailand (Part 1: Prevalence). J Med Assoc Thai 2000; 83: $872-879$.

14 Moreira ED Jr et al. Prevalence and correlates of erectile dysfunction: results of the Brazilian study of sexual behavior. Urology 2001; 58: 583-588. 